\title{
TL1A Selectively Enhances IL-12/IL-18-Induced NK Cell Cytotoxicity against NK-Resistant Tumor Targets
}

\author{
Stephanie C. Heidemann • Valerie Chavez • \\ Carol J. Landers • Torsten Kucharzik • John L. Prehn • \\ Stephan R. Targan
}

Received: 23 September 2009 / Accepted: 3 March 2010/Published online: 27 March 2010

(C) The Author(s) 2010. This article is published with open access at Springerlink.com

\begin{abstract}
Introduction TL1A (TNFSF15) augments IFN- $\gamma$ production by IL-12/IL-18 responsive human $\mathrm{T}$ cells. Its ligand, death domain receptor 3 (DR3), is induced by activation on T and NK cells. Although IL-12/IL-18 induces DR3 expression on most NK cells, addition of TL1A minimally increases IFN- $\gamma$ production.

Methods ${ }^{51}$ Chromium release and flow cytometric analysis were used to determine whether the TL1A-DR3 pathway is implicated in tumor cell lysis. Our aim was to determine whether the TL1A-DR3 pathway is implicated in tumor cell lysis.

Results TL1A had no additional effect on IL-12/IL-18induced cytotoxicity against an NK-susceptible tumor (K562); however, it promoted cytotoxicity against NKresistant targets susceptible to lysis only by activated NK cells. Discussion With IL-12/IL-18 activation, TL1A increased CD107a expression on NK cells which led to enhanced lysis of Daudi by PBMC and purified NK cells. To a lesser degree, TL1A increased lysis of colorectal adenocarcinoma epithelial derived lines (WiDr and SW837) by IL-12/IL-18-activated cells.
\end{abstract}

Stephanie C. Heidemann and Valerie Chavez contributed equally to the work presented here.

S. C. Heidemann · T. Kucharzik

Department of Medicine B, University of Muenster,

Albert-Schweitzer-Straße 33,

48149 Münster, Germany

S. C. Heidemann • V. Chavez • C. J. Landers · J. L. Prehn •

S. R. Targan $(\bowtie)$

Inflammatory Bowel Disease Research Center,

Cedars-Sinai Medical Center,

8700 Beverly Blvd., D4063,

Los Angeles, CA 90048, USA

e-mail: targans@cshs.org
Conclusion TL1A increased cytotoxicity of IL-12/IL-18activated NK cells against target cells dependent on NK activation for lysis and could function in vivo as a key coactivator of NK cytotoxicity.

Keywords Natural killer cells · cytotoxicity · cytokines · tumor immunity

\section{Introduction}

Natural killer cells $\left(\mathrm{CD}^{2} 6^{+}, \mathrm{CD}^{-}\right)$play an important role in innate immune defense by eliminating pathogen-infected and tumor cells through cytokine production and cytotoxicity. NK cell effector function is the result of an integration of signals from MHC class I-specific inhibitory receptors and several types of activating receptors, including a variety of co-stimulatory and adhesion molecules [11, 18, 32]. Cytotoxicity of NK cells is mediated through the $\mathrm{Ca}^{2+}$-dependent granule exocytosis pathway involving perforin/granzyme release and target lysis or through a $\mathrm{Ca}^{2+}$-independent mechanism involving Fas/CD95L-mediated apoptosis. A role for TNF Related Aptosis Inducing Ligand (TRAIL) and other TNF-family ligands in apoptosis of tumor targets by NK cells has been described [13, 29].

IL-12 stimulates NK cells, inducing IFN- $\gamma$ production $[5,14]$ enhancing cytolytic activity [6] and stimulating proliferation [12]. IL-18 also enhances NK lytic activity, and IL-18-deficient mice show impaired NK cell activity, as do IL-12-deficient mice. In mice lacking both cytokines, NK lytic activity is further impaired, indicative of IL-12 and IL-18 synergy in vivo [28]. NK cells, unlike T cells, constitutively express high-affinity receptors for both cytokines.

We reported that the TNF superfamily member TL1A synergized with IL-12/IL-18 to augment IFN- $\gamma$ production 
in resting human $\mathrm{PB} T$ and NK cells [23]. Since its identification, TL1A has been suggested to play a role in several inflammatory diseases. A partial, and in some cases substantial, inhibition of disease symptoms in mouse models of colitis, asthma, arthritis, and experimental autoimmune encephalitis is seen in mice in which TL1A is either attenuated with an antibody or knocked out. This attenuation of disease is also seen in disease models where the TL1A receptor, DR3 (TNFSFR25), is knocked out [4, 9, 19, 25].

DR3 is not expressed on unstimulated T and NK cells, but it is induced on a small subset of T cells and on up to $70 \%$ of NK cells by IL-12 and IL-18. However, while engagement of DR3 by TL1A augments IL-12/IL-18-induced IFN- $\gamma$ production 3-15-fold in T-cell cultures, the increase in NK cell cultures is a modest 2-fold and is due solely to stimulation of NK proliferation, not to increased IFN- $\gamma$ production per cell. Given the induction of DR3 on most NK cells by IL-12/IL18 , we, therefore, investigated whether TL1A also regulates another function of cytokine-activated NK cells, cytotoxicity against tumor cells.

In the present study, we show that TL1A, while not affecting lysis of NK-sensitive K562 cells, augments IL-12/ IL-18-induced NK cell cytotoxicity against NK-resistant Daudi cells independent of the possible effects of induced IFN- $\gamma$ and to a lesser degree the lysis of the colorectal adenocarcinoma epithelial derived cell lines WiDr and SW837. Thus, TL1A can augment the cytotoxicity of IL12/IL-18-activated NK cells against transformed cell targets susceptible to lysis only by activated NK cells. These results suggest that TL1A could play an important amplifying role in NK surveillance of certain tumors based on NK resistance.

\section{Methods}

Cytokines and Antibodies

Recombinant TL1A (aa 72-251) and anti-DR3 antibody (clone 01F05) were generated and tested for specificity at Teva Pharmaceuticals. Recombinant IL-12 (Peprotech, Rocky Hill, NJ) was used at $40 \mathrm{pg} / \mathrm{ml}$ except for the initial experiment (Fig. 1a) where it was used at $1 \mathrm{ng} / \mathrm{ml}$ for PBMC and $0.4 \mathrm{ng} / \mathrm{ml}$ for NK cells. IL-18 (R\&D Systems, Minneapolis, MN) was used at $54 \mathrm{ng} / \mathrm{ml}$ in all experiments. The cytokines tested for the induction of DR3 expression on NK cells were used at concentrations as follows: recombinant IFN- $\alpha$, IFN- $\beta$, IFN- $\gamma$, and IL-2 (Peprotech), $200 \mathrm{U} / \mathrm{ml}$; recombinant IL-15 and TNF- $\alpha$ (R\&D Systems), 50 and $10 \mathrm{ng} / \mathrm{ml}$, respectively; and Phorbol 12-myristate 13-acetate (PMA) and ionomycin (Sigma-Aldrich Inc., St. Louis, MO), 10 and $0.2 \mu \mathrm{g} / \mathrm{ml}$, respectively. Isotype- or species-specific control antibodies were from Jackson ImmunoResearch (West Grove, PA), anti-CD3 and-CD56 fluorochrome-conjugated $\mathrm{mAbs}$ were from Caltag (South San Francisco, CA), and anti-CD107a was from eBioscience (San Diego, CA).

\section{PBMC Isolation and Culture}

Blood was obtained from normal donors in accordance with the Human Subjects policy of the Cedars-Sinai Medical Center Institutional Review Board. PBMC were isolated on standard Ficoll-Hypaque density gradients and depleted of monocytes by adherence for $2 \mathrm{~h}$. NK cells isolated from PBMC by negative selection (NK cell isolation kit, Miltenyi Biotec, Auburn, CA), and thus not exposed to potentially stimulatory $\mathrm{mAb}$, yielded a population greater than $95 \%$ CD56+, CD3- NK cells. For some experiments, the cells retained in the column were eluted and tested as the non-NK fraction. PBMC, purified NK cells, and the non-NK fraction were cultured at $0.5 \times 10^{6}$ cells $/ \mathrm{ml}$ in RPMI 1,640 containing $2 \mathrm{mM}$ glutamine and $25 \mathrm{mM}$ HEPES buffer (Mediatech Inc., Herndon, VA), supplemented with $10 \%$ fetal bovine serum (Atlanta Biologicals, Norcross, $\mathrm{GA}$, heat inactivated) and gentamycin $(50 \mu \mathrm{g} / \mathrm{ml}$, Omega Scientific, Tarzana, CA) under conditions stated in the figures. Supernatants were frozen for IFN- $\gamma$ analysis by ELISA.

\section{Tumor Cell Lines}

The cell lines K562 (chronic myelogenous leukemia, ATCC CCL 243), Daudi (Burkitt's lymphoma, ATCC CCL 213), and SW837 (rectal adenocarcinoma, ATCC CCL 235) were all grown in RPMI 1,640 supplemented as indicated above. WiDr cells (colorectal adenocarcinoma, ATCC CCL 218) were cultured in Minimum Essential Medium Eagle with Earle's salts and $l$ glutamine (Mediatech, Inc., Herndon, VA), with 10\% fetal bovine serum and gentamycin. The leukemic suspension cell lines were used in the log phase of growth and the adherent epithelial cell lines when reaching $70 \%$ confluency, harvested by using Trypsin EDTA $(0.25 \%$ Trypsin and $1 \mathrm{mM}$ EDTA-4Na, Gibco Invitrogen Corp., Grand Island, NY) according to ATCC protocols.

\section{Cell Staining for Flow Cytometry}

To study surface DR3 expression on NK cells, PBMC were blocked with goat IgG for 20 min on ice and incubated with anti-DR3-specific monoclonal or isotype control antibody on ice. The cells were then washed with $\mathrm{PBS} / 0.5 \%$ BSA and incubated with anti-mouse secondary antibody conjugated to phycoerythrin (Caltag, Burlingame, CA) for 
Fig. 1 TL1A synergizes with IL-12 and IL-18 to increase IFN- $\gamma$ production in PBMC and NK cells but does not enhance cytolytic activity of PBMC and NK cells against the NKsensitive K562 cell line. a PBMC and purified NK cells were cultured with medium (Control) or a maximal concentration of IL-12 and IL-18 without or with TL1A $(50 \mathrm{ng} / \mathrm{ml})$, and their cytotoxicity was tested against the NK-sensitive cell line $\mathrm{K} 562$ in ${ }^{51} \mathrm{Cr}$-release assays and expressed in lytic units $\left(\mathrm{LU}_{30}\right.$, left panels). Culture supernatants were collected at $72 \mathrm{~h}$ and analyzed for IFN- $\gamma$ content by ELISA (right pan$e l s)$. Results are representative of two experiments with similar results. b PBMC and purified NK cells of the same donor were cultured as in $1 \mathrm{~A}$ but with a lower IL-12 concentration $(40 \mathrm{pg} / \mathrm{ml})$. Results are representative of three experiments for PBMC, two experiments for NK cells. TL1A-treated PBMC produced significantly more IFN- $\gamma(p=0.05)$ while no significant difference was seen in cytotoxicity. $\mathrm{LU}_{30}$, the number of effector cells required to lyse $30 \%$ of a standard number of target cells, here $10^{4}$ target cells. Bars SD
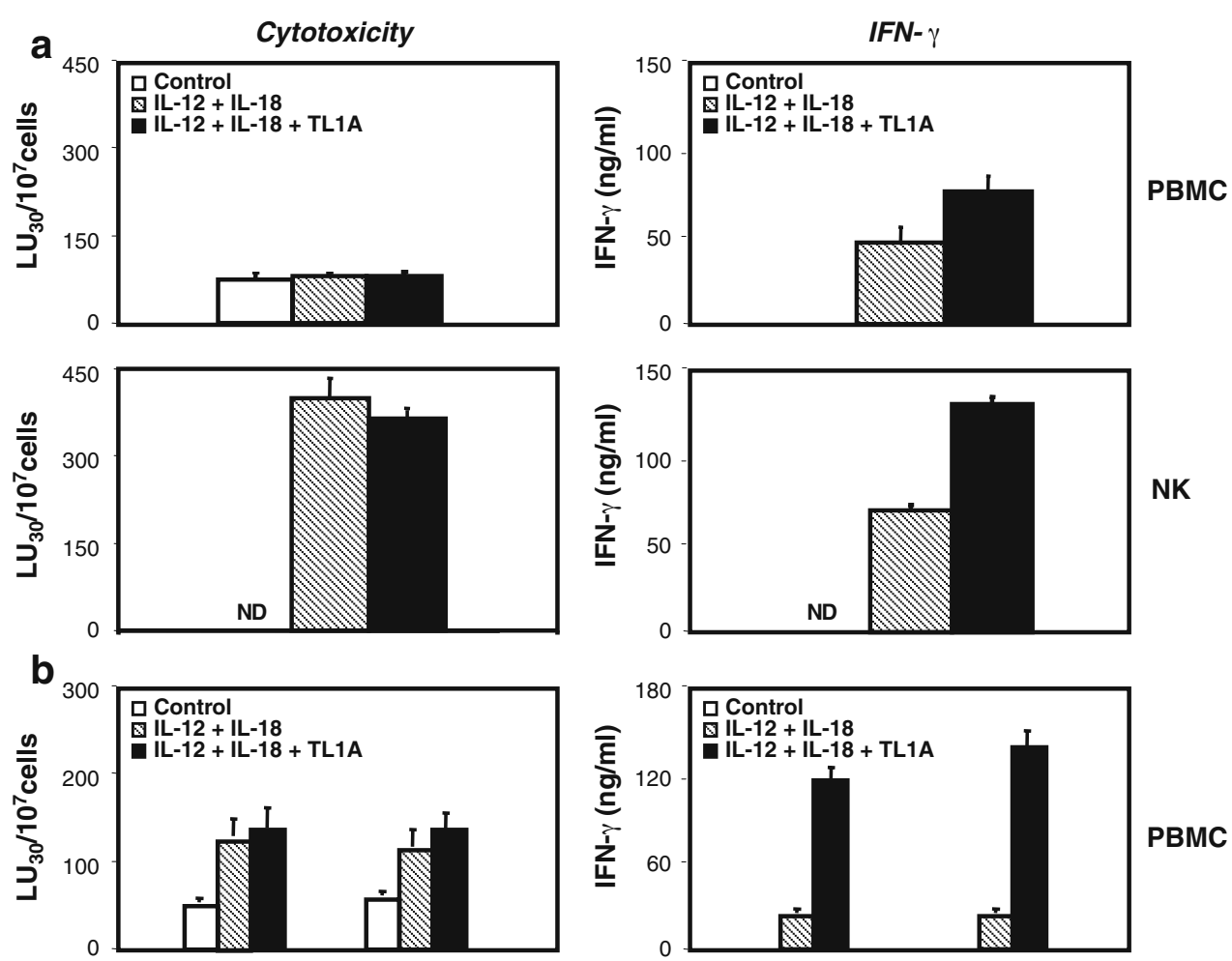

PBMC
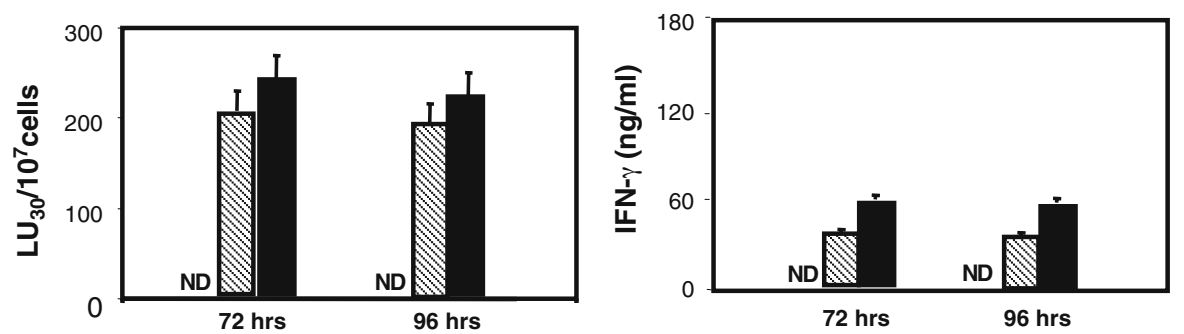

30 min on ice. After washing with PBS/BSA and blocking with mouse IgG for $20 \mathrm{~min}$, cells were stained with CD3FITC and CD56-tricolor (TC) for $20 \mathrm{~min}$ on ice and analyzed by flow cytometry (Becton Dickinson, Mountain View, CA). DR3 expression was analyzed on NK cells by gating on lymphocytes based on forward and side scatter and further gating on CD3-CD56+ cells; $5 \times 10^{4}$ cells were acquired and both the percentage of NK cells expressing DR3 and the mean fluorescence intensity of DR3+ cells were obtained. Percentage nonspecific staining by isotype control $\mathrm{Ab}$ or percentage specific staining of the control condition, respectively, was subtracted from percentagespecific staining of the test condition, as indicated in the figure legends.

\section{Detection of IFN- $\gamma$ by ELISA}

IFN- $\gamma$ in culture supernatants was detected by amplified sandwich ELISA and quantitated as previously reported [31].

\section{Cytotoxicity Assay}

Cytolytic activity was determined by 2 to 3 -h ${ }^{51} \mathrm{Cr}$-release assays [10]. K562, Daudi, SW837, and WiDr were used as target cells. NK cells, non-NK cells, and PBMC were used as effector cells. Target cell pellets $\left(3 \times 10^{6}\right.$ cells $)$ were labeled with $150 \mu \mathrm{Ci}$ of $\mathrm{Na}_{2}{ }^{51} \mathrm{CrO}_{4}$ (Perkin Elmer, Boston, MA) at $37^{\circ} \mathrm{C}$ for $1 \mathrm{~h}$. The target cells were washed twice with Hanks' Buffered Salt Solution (Mediatech Inc., Herndon, VA) and $10^{4}$ cells/well were incubated in $200 \mu \mathrm{l}$ RPMI 1,640 medium (specified above) with effector cells at six different effector/target $(\mathrm{E} / \mathrm{T})$ ratios, ranging from 14:1 to $100: 1$ for PBMC and the non-NK cell fraction and 1.4:1 to $10: 1$ for purified NK cells. Wells containing target cells alone were used to determine spontaneous release, and $10 \%$ Triton X-100 was added to determine maximum target ${ }^{51} \mathrm{Cr}$ release. Assay plates were centrifuged briefly and incubated at $37^{\circ} \mathrm{C}$ for 2 to $3 \mathrm{~h} .{ }^{51} \mathrm{Cr}$ released into supernatants by lysed target cells was measured in a gamma counter and mean cpm calculated. The data are presented as lytic units 
(LU) $)_{30} / 10^{7}$ effectors. Percent specific lysis and lytic units were calculated using a computer program developed by R. Deem. The following formula was used to calculate the percent specific lysis:

$\mathrm{PSL}=[(\mathrm{ER}-\mathrm{SR}) /(\mathrm{MR}-\mathrm{SR})] \times 100$

where ER denotes the experimental release, SR is the spontaneous release, and MR is the maximal release. Lytic units were calculated as:

\section{$\mathrm{LU}_{30} / 10^{7}$ cells $=\mathrm{E}_{\mathrm{STD}} /\left(\mathrm{E} / \mathrm{T}_{30}\right) \times\left(\mathrm{T}_{\mathrm{STD}}\right)$}

in which $\mathrm{E}_{\mathrm{STD}}$ is $10^{7}$ effector cells, $\mathrm{E} / \mathrm{T}_{30}$ is the $\mathrm{E} / \mathrm{T}$ ratio at which $30 \%$ of the target cells are killed and $\mathrm{T}_{\mathrm{STD}}$ is $10^{4}$ target cells. For flow cytometric cytotoxicity, the same protocol was followed, substituting target cells labeled with 5- (and 6)-carboxyfluorescein diacetate succinimidyl ester (CFSE, $1 \mu \mathrm{M}$, eBioscience) for $10 \mathrm{~min}$ at room temperature per manufacturer's instructions in place of those labeled by ${ }^{51} \mathrm{Cr}$. IFN- $\gamma$ blocking antibody (clone NIB42, BD Biosciences, San Jose, CA) or isotype specific control antibody (eBioscience, San Diego) was added at $5 \mu \mathrm{g} / \mathrm{ml}$. At the end of the $2 \mathrm{~h}$ assay, three to four wells for each E/T ratio were combined and stained with anti-CD107a and 7-aminoactinomycin D (7-AAD, eBioscience, $1.25 \mu \mathrm{g} / \mathrm{ml})$. Targets were gated by size (forward angle light scatter (FSC)) and CFSE with cytotoxicity assessed as the $\% 7-\mathrm{AAD}^{+} / \mathrm{CFSE}^{+}$. Lytic units were calculated using a linear regression of the

Table 1 Other Known NK Cell Activating Stimuli Do Not Upregulate DR3 Expression

\begin{tabular}{|c|c|}
\hline Culture condition & $\%$ DR3-positive NK cells \\
\hline Control & 5.3 \\
\hline IFN- $\gamma$ & 3.9 \\
\hline IFN- $\beta$ & 5.4 \\
\hline IFN- $\alpha$ IFN- $\beta$ & 8.9 \\
\hline IFN- $\alpha$ IFN- $\beta$ IL- 12 & 6.2 \\
\hline PMA+Ionomycin & 1.3 \\
\hline IL-15 & 7.5 \\
\hline IL-2 & 7.3 \\
\hline IL-2+IL-15 & 1.9 \\
\hline IL-2+IL-12 & 0.6 \\
\hline IFN- $\gamma$ & 8.6 \\
\hline TNF- $\alpha$ & 5.0 \\
\hline IL-12 (1 ng/ml)+IL-18 & 64.6 \\
\hline IL-12 (40 pg/ml)+IL-18 & 40.0 \\
\hline
\end{tabular}

PBMC were incubated with medium (Control) or with cytokines alone or in combination as indicated for $48 \mathrm{~h}$ or with PMA + Ionomycin for $18 \mathrm{~h}$, stained indirectly for DR3 ("Methods"), and analyzed by flow cytometry

Percentage of DR3-specific staining in the NK cell population in one representative experiment of two with similar results

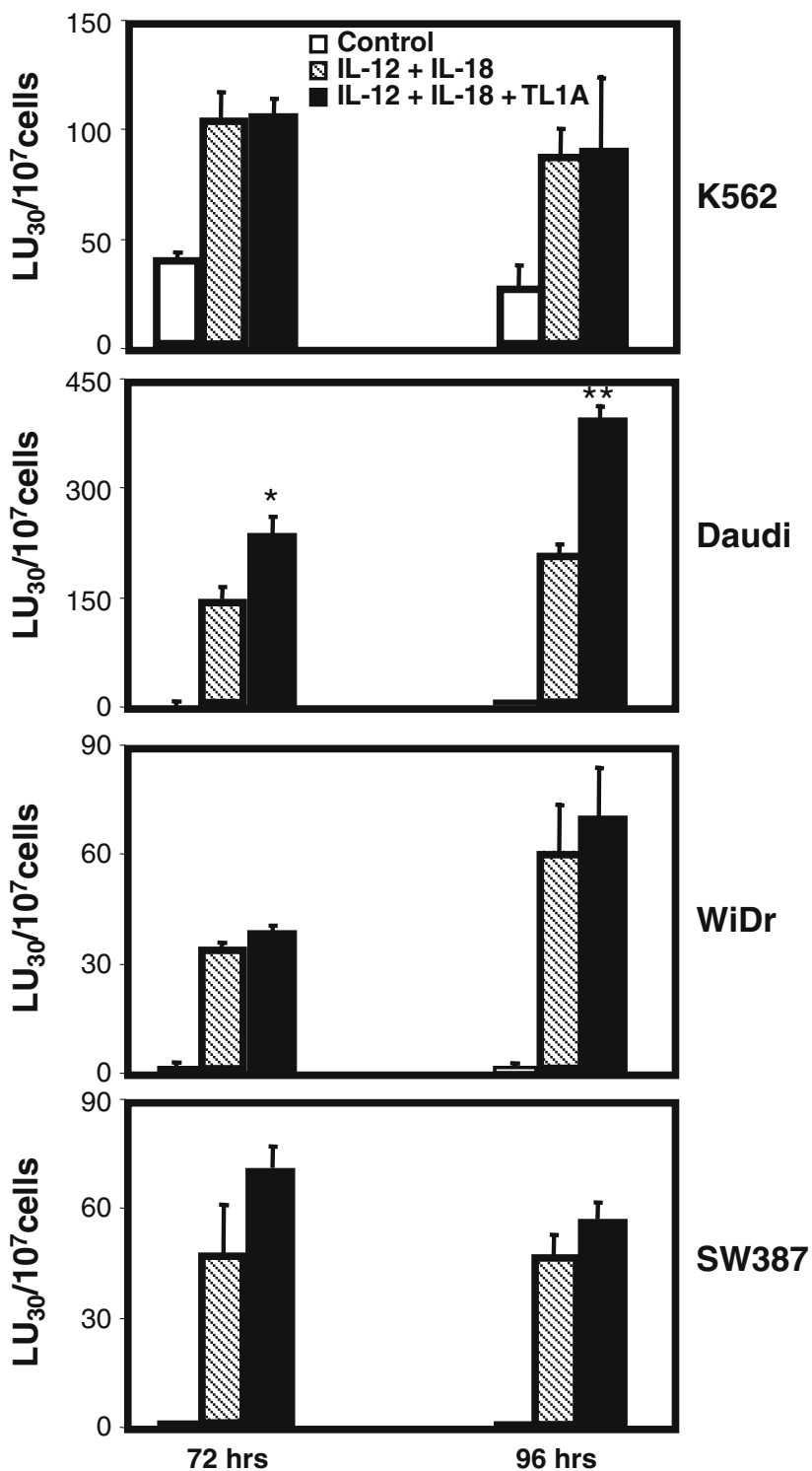

Fig. 2 TL1A enhances NK cell cytotoxicity against NK-resistant cell lines, particularly against Daudi cells. PBMC were cultured and then tested for cytotoxicity to the NK-resistant target cells Daudi $(n=7)$, WiDr $(n=3)$, and SW837 $(n=3)$ in ${ }^{51} \mathrm{Cr}$-release assays (lower three panels) and compared to the cytotoxicity toward K562 cells ( $n=3$, upper panel). TL1A-treated PBMC were significantly more cytotoxic to Daudi cells than that induced by PBMC and IL-12/IL-18 alone $(* p<0.0004$ at $72 \mathrm{~h}$ and $* * p<0.009$ at $96 \mathrm{~h})$. Mean values and SEM are shown

individual cytotoxicity measurements. NK expression of CD107a was based on $\mathrm{CFSE}^{-}$cells gated by FSC.

Statistical Analysis

The paired $t$ test was performed using JMP IN 5.1 data analysis software to determine the significance of the difference in cytotoxicity of IL-12/IL-18-treated PBMC without and with TL1A. 


\section{Results}

DR3 is Induced on NK Cells by IL-12/IL-18, but not by Other NK-stimulating Cytokines

DR3 is the receptor for TL1A, the only DR3-ligand of several tested by Migone et al. [20]. In a previous study, we showed that DR3 expression could be induced on up to $70 \%$ of NK cells by maximally effective concentrations of the combined cytokines IL-12 and IL-18 [23]. Other cytokines known to activate NK cells might also induce DR3 expression, but only IL-12/IL-18, of a panel of cytokines and cytokine combinations that we tested were capable of significant induction of DR3 (Table 1).

\section{TL1A Does Not Enhance Cytotoxicity} against NK-Sensitive K562 Target Cells

We demonstrated previously that TL1A augments IL-12/IL18 -induced IFN- $\gamma$ production in NK cells by about 2 -fold, largely due to NK proliferation [23]. Given the dramatic induction by IL-12/IL-18 of DR3 on NK cells, we hypothesized that TL1A might affect another NK effector function, cytotoxicity, as well as IFN- $\gamma$ production.

While the TL1A/DR3 pathway was functional as evidenced by enhanced IFN- $\gamma$ production in response to TL1A by cells cultured with IL-12 and IL-18 (Fig. 1a, right panels: 2.1-fold increase in PBMC and 2.4-fold increase for NK cells), there was no significant difference in cytolytic activity with TL1A at supra-maximal IL-12/IL-18 concentrations (Fig. 1a, left panels). These concentrations, while strongly inducing DR3, might maximize NK cell cytotoxicity (Fig. 1a, left panels) and thus obscure an effect of TL1A on NK cell cytotoxicity. Therefore, we sought to determine whether a lower concentration of IL-12 (with maintained IL-18) would effectively induce DR3 expression on NK and perhaps not maximally stimulate cytotoxicity. Lowering IL-12 concentration to $40 \mathrm{pg} / \mathrm{ml}$ still resulted in DR3 induction on $40 \%$ of NK cells (Table 1) with no decrease in MFI (data not shown), so we tested this concentration in cytotoxicity experiments (Fig. 1b, left panels). Our results demonstrated that cytotoxicity was not
Fig. 3 TL1A enhancement of IL-12/IL-18-induced cytotoxicity to Daudi cells is mediated mainly by NK cells. a, b Purified NK (a) and the non-NK fraction (b) from the same donor were cultured, and their cytolytic activity was tested against Daudi in a ${ }^{51} \mathrm{Cr}$-release assay. c, d IFN- $\gamma$ production by purified NK (c) and non-NK cells (d) from four different donors was measured with and without TL1A. Mean values and SEM of two experiments are shown for the lytic activity. Individual donor results for IFN- $\gamma$ production and the fold increase for each donor are shown. The average fold increase for the four donors is displayed on the side of each figure

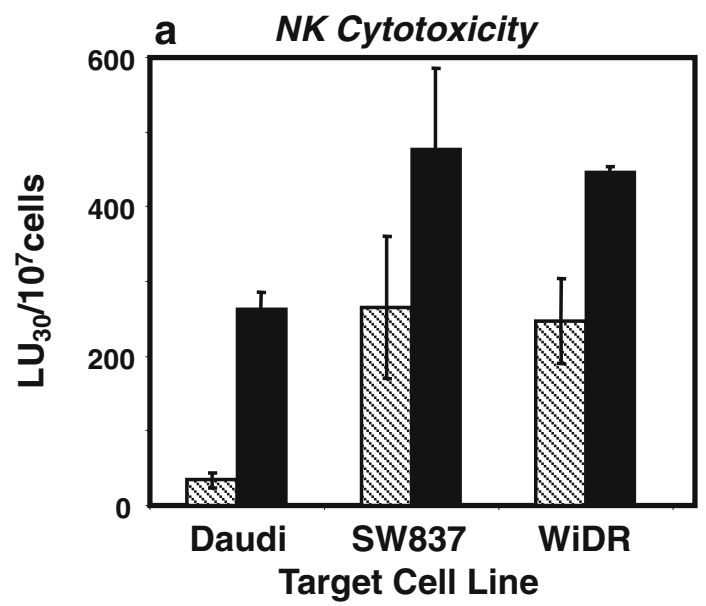

b Non-NK Cytotoxicity

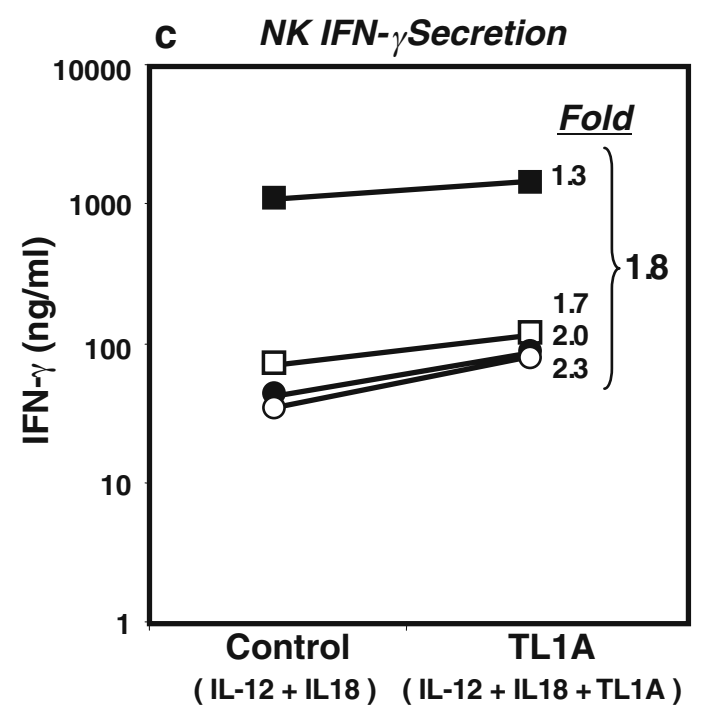

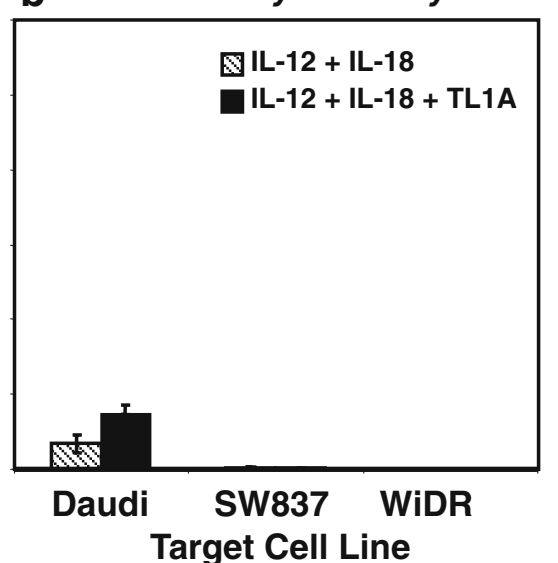

d Non-NK IFN Secretion

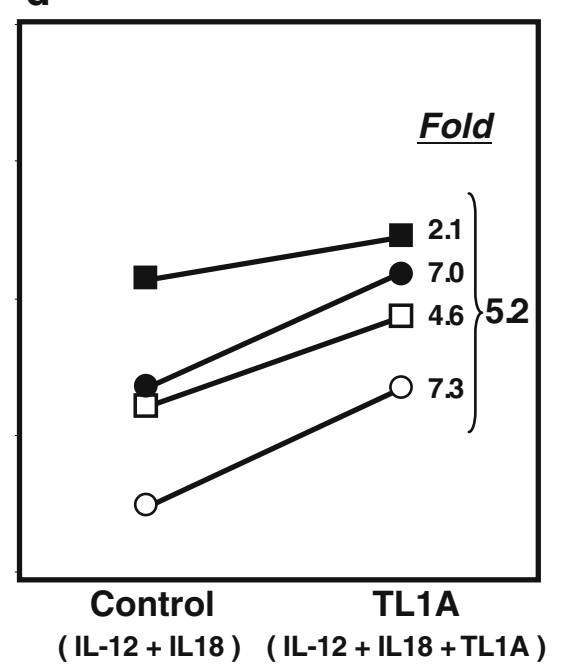


decreased, and TL1A still did not significantly enhance IL12/IL-18-induced cytolytic activity of PBMC and NK cells. Additionally, at this lower level of IL-12, the effect of TL1A on IFN- $\gamma$ production was unimpaired in isolated NK cells or even enhanced in PBMC relative to control (Fig. 1b, right panels).

This set of results led us to the notion that TL1A might enhance NK cell-mediated tumor lysis over a more prolonged time-course. We, therefore, examined the effect of TL1A on NK cytotoxicity in the same conditions for 96, 120 , and $144 \mathrm{~h}$. No significant difference in NK cell cytotoxicity against K562 targets was detected with and without TL1A (Fig. 1 and data not shown).

TL1A Enhances NK Cell Cytotoxicity against Cell Lines, In Particular Daudi, Which are Lysed only by Activated NK Cells

Cells from the K562 cell line are the commonly used target cell for ${ }^{51} \mathrm{Cr}$-release assays using freshly isolated, unstimulated PBMC or NK cells, while Daudi cells, which are resistant to lysis by fresh NK cells, are used for assays of cytotoxicity mediated by activated NK cells [10]. We investigated whether TL1A had an effect on NK cell lytic activity against the NK-resistant target cell lines Daudi, SW837, and WiDr (Fig. 2). For PBMC, TL1A had the most profound effect against Daudi target cells, enhancing cytotoxicity 2-fold at $96 \mathrm{~h}$ of incubation (second panel). The effect of TL1A on IL-12/IL-18-induced cytotoxicity of PBMC against the NK-resistant epithelial cell lines WiDr and SW837 showed a similar but not statistically significant trend (Fig. 2, third and fourth panel).

Because T lymphocytes present in PBMC are capable of lysing Daudi target cells [8], we wanted to clarify whether our results with PBMC resulted from NK or non-NK cell cytotoxicity. Using magnetic cell separation, we tested the lytic activity of purified NK cells, compared to the non-NK cell fraction, on the Daudi, SW837, and WiDR cells (Fig. 3a and b). While the non-NK population, which included CD56+ $\mathrm{T}$ cells, displayed some IL12/IL18induced cytotoxicity against Daudi cells, which was enhanced by TL1A (Fig. 3b), TL1A had the most significant effect on the lytic activity of purified NK cells (Fig. 3a) where it augmented cytotoxicity by 7 -fold in Daudi cells compared to a 1.8-fold increase in NK cell IFN$\gamma$ production (Fig. 3c). Comparatively, TL1A enhanced NK lytic activity on the SW837 and WiDR cell lines, but to a lesser degree, perhaps due to a much larger induction of cytotoxicity by IL12/IL18. In contrast, in non-NK cells (Fig. 3b) consisting mostly of T cells, TL1A increased cytotoxicity by only 2 -fold over IL12/18 alone in the Daudi cells, and little to no activity was detected in the SW837 and WiDR cells. IFN- $\gamma$ production in the non-NK cell population increased an average of 5.2-fold in the presence of TL1A. Together, these results suggest that the enhancing effect of TL1A on the cytotoxicity of PBMC against the Daudi and likely the SW837 and WiDr cell lines are mediated mainly by augmenting the cytotoxicity of IL-12/ IL-18-activated NK cells.

\section{TL1A-Enhanced Cytolytic Activity is Not Due to IFN- $\gamma$ Production}

Given that TL1A induces increased production of IFN- $\gamma$, it is possible that the increased cytotoxicity seen with Daudi is an indirect effect, mediated through IFN- $\gamma$. To address

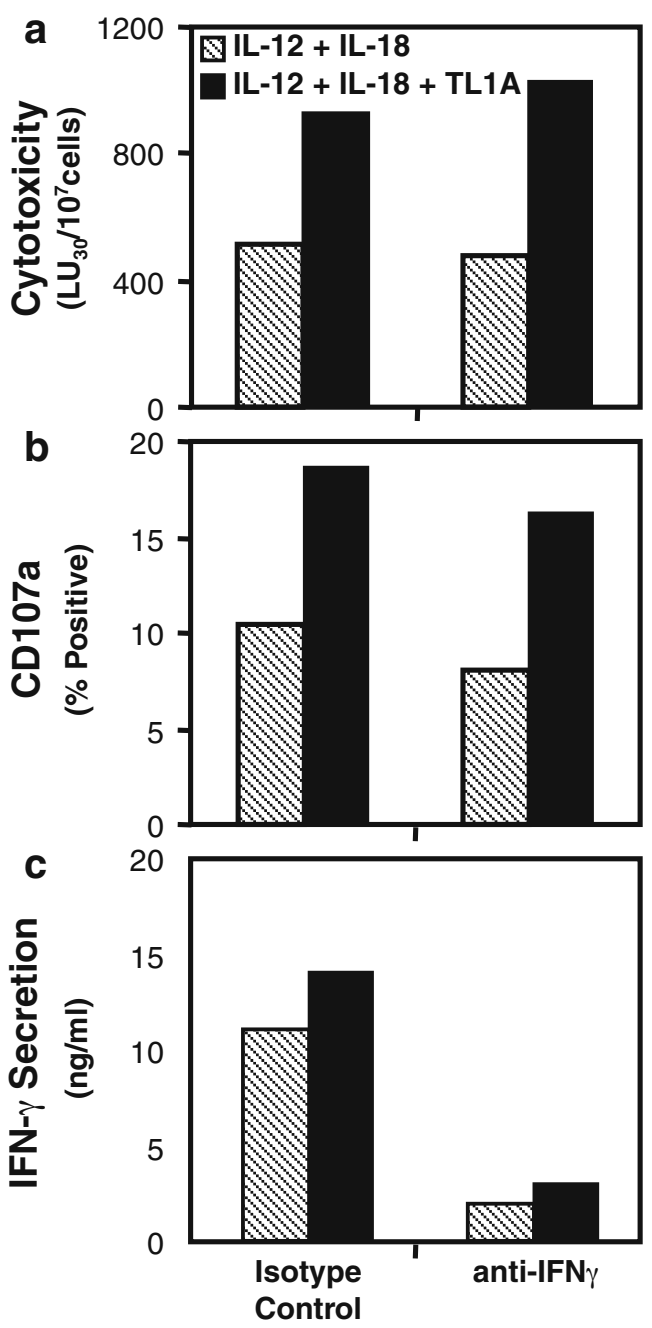

Fig. 4 TL1A enhancement of IL-12/IL-18-induced cytotoxicity to Daudi cells is marked by increased surface expression of CD107a and is not significantly affected by the presence of IFN- $\gamma$. Purified NK were cultured for $72 \mathrm{~h}$ with IL-12 and IL-18 with or without TL1A $(20 \mathrm{ng} / \mathrm{ml})$, and their cytolytic activity (a) was tested against Daudi under IFN- $\gamma$ blocking conditions in a FCC assay in which CD107a expression (b) was concurrently assessed. Production of IFN during the $2 \mathrm{~h}$ assay period was also monitored (c). Representative results for two experiments are shown 
this concern, we tested the lytic activity of purified NK cells in the presence of IFN- $\gamma$ blocking antibody in a flow cytometric cytotoxicity assay [16]. This allowed us to assess IFN- $\gamma$ production during the 2-h cytotoxicity assay and also simultaneously measure lysosomal-associated membrane protein-1 (LAMP-1, CD107a), a marker associated with increased cytotoxic activity $[1,2]$. As seen in Fig. $4 \mathrm{a}$ and $\mathrm{c}$, cytolytic activity was unchanged by the blocking conditions for both IL-12/IL-18 and IL-12/IL18 + TL1A despite a 5-fold reduction in the concentration of IFN- $\gamma$. CD107a expression was increased with IL-12/IL-18 (data not shown), further increased with TL1A and was also unaffected by IFN- $\gamma$ blockade (Fig. 4b), supporting the concept that TL1A directly enhances the cytolytic potential of NK cells.

\section{Discussion}

Our results show that TL1A significantly enhances the cytolytic activity of NK cells costimulated by IL-12/IL-18 against the NK resistant leukemic Daudi targets and to a lesser degree against WiDr and SW837 epithelial tumor cells. Although only a few target cell lines (K562, Daudi, WiDr, and SW837) were tested for susceptibility to lysis by PBMC or purified NK cells activated by IL-12/IL-18 without and with TL1A, the results suggest that TL1A preferentially potentiates lytic activity of activated NK cells against otherwise NK-resistant targets (Daudi, WiDr, and SW837), while not increasing the already substantial cytolytic activity against NK-sensitive targets (K562). Whether the relative greater enhancement of the NK cell lysis by the hematopoetic tumor cell Daudi compared to the solid epithelial tumors suggests a more potent effect of TL1A on this class of tumors will require further study. Interestingly, TL1A resulted in a 2-fold increase in cytotoxicity of non-NK cells, largely $\mathrm{T}$ cells, and thus, the effect of TL1A on cytotoxicity is not limited to NK cells.

Since augmentation of cytotoxicity against NK-resistant targets by TL1A is dependent on IL-12/IL-18, TL1A could contribute to IL-12/IL-18-induced modulations of NK lytic mechanisms and/or NK-target cell recognition and NK activation. In this context, we have shown that TL1A does increase the surface expression of LAMP-1 on NK cells costimulated with IL-12/IL-18. LAMP-1 expression is associated with both NK cytotoxicity and IFN- $\gamma$ secretion $[1,2]$ and may be related to induction of other factors influential in NK killing. Cytokine stimulations such as IL2, IL-12, and IL-18 have also been shown to enhance perforin binding to the target cell membrane [17], increase the expression of the natural cytotoxicity receptor NKp44 [21], alter the NKG2D receptor activity [3, 7, 26, 27], and override signals from the inhibitory Ly49G2 receptor $[15$,
22]. It remains to be seen if TL1A plays a role in any of these mechanisms. Although IFN- $\gamma$ has been shown to play an important role in the modulation of key surface receptors or ligands (e.g., MHC class I, Fas, and TRAIL), our results show the IFN- $\gamma$ levels produced with TL1A do not seem to be involved in TL1A-induced cytotoxicity.

TL1A has been shown to play an important role in modulating the adaptive immune response, both in Th1 (murine colitis [30]) and Th2 (allergic lung inflammation [9]) disease models as well as a Th17-mediated autoimmune disease model [24], making the TL1A pathway an attractive target for potential therapy. Our results suggest that care should be taken such that immune surveillance of hematopoietic tumors is not compromised with anti-TL1A therapeutics.

\section{Conclusions}

We demonstrated that TL1A selectively enhances IL-12/IL18-induced NK cell cytotoxicity against Daudi cells and other NK-resistant tumor targets, thereby potentiating the cytolytic activity of activated NK cells independent of IFN$\gamma$. The signaling pathways involved in TL1A enhancement of IL-12/IL-18-induced cytotoxicity and the mechanisms underlying its preferential effect on NK cell-mediated lysis of resistant targets deserve further studies and may elucidate a possible role for TL1A in tumor surveillance and therapy.

Acknowledgments This work was supported by USPHS Grant DK056328.

We thank Offer Cohavy and Loren Karp for helpful discussions and critical reading of the manuscript.

Open Access This article is distributed under the terms of the Creative Commons Attribution Noncommercial License which permits any noncommercial use, distribution, and reproduction in any medium, provided the original author(s) and source are credited.

\section{References}

1. Aktas E, Kucuksezer UC, Bilgic S, Erten G, Deniz G. Relationship between CD107a expression and cytotoxic activity. Cell Immunol. 2009;254:149-54.

2. Alter G, Malenfant JM, Altfeld M. CD107a as a functional marker for the identification of natural killer cell activity. J Immunol Methods. 2004;294:15-22.

3. Andre P, Castriconi R, Espeli M, Anfossi N, Juarez T, Hue S, et al. Comparative analysis of human NK cell activation induced by NKG2D and natural cytotoxicity receptors. Eur J Immunol. 2004;34:961-71.

4. Bull MJ, Williams AS, Mecklenburgh Z, Calder CJ, Twohig JP, Elford C, et al. The death receptor 3-TNF-like protein 1A pathway drives adverse bone pathology in inflammatory arthritis. J Exp Med. 2008;205:2457-64. 
5. Chan SH, Perussia B, Gupta JW, Kobayashi M, Pospisil M, Young HA, et al. Induction of interferon gamma production by natural killer cell stimulatory factor: characterization of the responder cells and synergy with other inducers. J Exp Med. 1991;173:869-79.

6. Chehimi J, Valiante NM, D'Andrea A, Rengaraju M, Rosado Z, Kobayashi M, et al. Enhancing effect of natural killer cell stimulatory factor (NKSF/interleukin-12) on cell-mediated cytotoxicity against tumor-derived and virus-infected cells. Eur J Immunol. 1993;23:1826-30.

7. Cosman D, Mullberg J, Sutherland CL, Chin W, Armitage R, Fanslow W, et al. ULBPs, novel MHC class I-related molecules, bind to CMV glycoprotein UL16 and stimulate NK cytotoxicity through the NKG2D receptor. Immunity. 2001;14:123-33.

8. Costello RT, Fauriat C, Sivori S, Marcenaro E, Olive D. NK cells: innate immunity against hematological malignancies? Trends Immunol. 2004;25:328-33.

9. Fang L, Adkins B, Deyev V, Podack ER. Essential role of TNF receptor superfamily 25 (TNFRSF25) in the development of allergic lung inflammation. J Exp Med. 2008;205:1037-48.

10. Friberg DD, Bryant JL, Whiteside TL. Measurements of Natural Killer (NK) activity and NK-cell quantification. Methods. 1996;9:316-26.

11. Gasser S, Raulet DH. Activation and self-tolerance of natural killer cells. Immunol Rev. 2006;214:130-42.

12. Gately MK, Desai BB, Wolitzky AG, Quinn PM, Dwyer CM, Podlaski FJ, et al. Regulation of human lymphocyte proliferation by a heterodimeric cytokine, IL-12 (cytotoxic lymphocyte maturation factor). J Immunol. 1991;147:874-82.

13. Kashii Y, Giorda R, Herberman RB, Whiteside TL, Vujanovic NL. Constitutive expression and role of the TNF family ligands in apoptotic killing of tumor cells by human NK cells. J Immunol. 1999;163:5358-66.

14. Kobayashi M, Fitz L, Ryan M, Hewick RM, Clark SC, Chan S, et al. Identification and purification of natural killer cell stimulatory factor (NKSF), a cytokine with multiple biologic effects on human lymphocytes. J Exp Med. 1989;170:827-45.

15. Lanier LL. NK cell receptors. Annu Rev Immunol. 1998;16:359-93.

16. Lecoeur H, Fevrier M, Garcia S, Riviere Y, Gougeon ML. A novel flow cytometric assay for quantitation and multiparametric characterization of cell-mediated cytotoxicity. J Immunol Methods. 2001;253:177-87.

17. Lehmann C, Zeis M, Uharek L. Activation of natural killer cells with interleukin 2 (IL-2) and IL-12 increases perforin binding and subsequent lysis of tumour cells. Br J Haematol. 2001;114:660-5.

18. Long EO. Regulation of immune responses through inhibitory receptors. Annu Rev Immunol. 1999;17:875-904.

19. Meylan F, Davidson TS, Kahle E, Kinder M, Acharya K, Jankovic $\mathrm{D}$, et al. The TNF-family receptor DR3 is essential for diverse T cell-mediated inflammatory diseases. Immunity. 2008;29:79-89.
20. Migone TS, Zhang J, Luo X, Zhuang L, Chen C, Hu B, et al. TL1A is a TNF-like ligand for DR3 and TR6/DcR3 and functions as a $\mathrm{T}$ cell costimulator. Immunity. 2002;16:479-92.

21. Moretta A, Bottino C, Vitale M, Pende D, Cantoni C, Mingari $\mathrm{MC}$, et al. Activating receptors and coreceptors involved in human natural killer cell-mediated cytolysis. Annu Rev Immunol. 2001;19:197-223.

22. Ortaldo JR, Young HA. Expression of IFN-gamma upon triggering of activating Ly49D NK receptors in vitro and in vivo: costimulation with IL-12 or IL-18 overrides inhibitory receptors. J Immunol. 2003;170:1763-9.

23. Papadakis KA, Prehn JL, Landers C, Han Q, Luo X, Cha SC, et al. TL1A synergizes with IL-12 and IL-18 to enhance IFN-gamma production in human $\mathrm{T}$ cells and NK cells. J Immunol. 2004;172:7002-7.

24. Pappu BP, Angkasekwinai P, Dong C. Regulatory mechanisms of helper T cell differentiation: new lessons learned from interleukin 17 family cytokines. Pharmacol Ther. 2008;117:374-84.

25. Pappu BP, Borodovsky A, Zheng TS, Yang X, Wu P, Dong $\mathrm{X}$, et al. TL1A-DR3 interaction regulates Th17 cell function and Th17-mediated autoimmune disease. J Exp Med. 2008;205:1049-62.

26. Pende D, Cantoni C, Rivera P, Vitale M, Castriconi R, Marcenaro $\mathrm{S}$, et al. Role of NKG2D in tumor cell lysis mediated by human NK cells: cooperation with natural cytotoxicity receptors and capability of recognizing tumors of nonepithelial origin. Eur $\mathrm{J}$ Immunol. 2001;31:1076-86.

27. Pende D, Rivera P, Marcenaro S, Chang CC, Biassoni R, Conte R, et al. Major histocompatibility complex class I-related chain A and UL16-binding protein expression on tumor cell lines of different histotypes: analysis of tumor susceptibility to NKG2Ddependent natural killer cell cytotoxicity. Cancer Res. 2002;62:6178-86.

28. Takeda K, Tsutsui H, Yoshimoto T, Adachi O, Yoshida N, Kishimoto T, et al. Defective NK cell activity and Th1 response in IL-18-deficient mice. Immunity. 1998;8:383-90.

29. Takeda K, Hayakawa Y, Smyth MJ, Kayagaki N, Yamaguchi N, Kakuta S, et al. Involvement of tumor necrosis factor-related apoptosis-inducing ligand in surveillance of tumor metastasis by liver natural killer cells. Nat Med. 2001;7:94-100.

30. Takedatsu H, Michelsen KS, Wei B, Landers CJ, Thomas LS, Dhall D, et al. TL1A (TNFSF15) regulates the development of chronic colitis by modulating both T-helper 1 and T-helper 17 activation. Gastroenterology. 2008;135:552-67.

31. Targan SR, Deem RL, Liu M, Wang S, Nel A. Definition of a lamina propria $\mathrm{T}$ cell responsive state. Enhanced cytokine responsiveness of $\mathrm{T}$ cells stimulated through the CD2 pathway. $\mathrm{J}$ Immunol. 1995; 154:664-75.

32. Vivier E, Tomasello E, Baratin M, Walzer T, Ugolini S. Functions of natural killer cells. Nat Immunol. 2008;9:503-10. 